\title{
Nanoparticles Skin Exposure and Absorption: Differences between Children and Adults
}

\section{Marcella Mauro* \\ Department of Medical Sciences, University of Trieste, Italy}

*Corresponding author: Marcella Mauro, Department of Medical Sciences, University of Trieste, Centro Tumori, Via della Pietà, 2/2 34141 Trieste, Italy, Tel: +39

\section{Editorial}

Volume 3 Issue 2

Received Date: April 13, 2018

Published Date: April 23, 2018

3497896767; Email: mmauro@units.it/ marcella.mauro82@gmail.com

\section{Editorial}

Nanoparticles (NPs) are widespread in many fields of everyday life. Materials in nano-size range (below 100 $\mathrm{nm}$ ) acquire interesting new properties due to the higher surface per mass ratio, which are exploited by industries to produce highly specialised low-volume technical applications, targeted medical treatments and anti-cut or antibacterial textiles, to cite only some uses [1].

NPs transdermal absorption is being studied in the last years, since skin contact with a variety of items containing NPs is actually common in occupational and consumers settings. Based on the available data it can be state that only for a limited types of NPs both penetration and permeation through the skin has been demonstrated. NPs primary size and skin integrity are two crucial aspects as regard skin absorption and, for metal nanoparticles also the ionizing potential may play an important role in the bioavailability of the substance [2]. Despite the research efforts, NPs transdermal absorption has not yet been fully defined. Moreover experimental data derive in most cases from animal or human adult donor skin, thus findings are applicable only to predict the adult population transdermal permeation.

Children are commonly exposed to NPs, from the ones present in the environment as pollutants (e.g. Pt and $\mathrm{Rh}$ NPs from vehicles exhaust), to the ones used in sunscreens $\left(\mathrm{TiO}_{2} \mathrm{NPs}\right)$ and food packaging ( $\mathrm{Al}$ oxides NPs), passing through the ones used as antiseptic agents in childcare products, such as silver NPs (AgNPs) [3]. The latter case represents the exposure scenario most likely to happen in terms of availability and frequency of contacts for children population. AgNPs, in fact, are commonly present both in products used by children - such as pajamas baby blankets, plush toys - and also in items used around children - such as disinfecting sprays, surface wipes and kitchen scrubbers [3].

Children's skin significantly differs from the one of adults and so the available Nanotoxicological knowledge cannot predict infant's dermal absorption. Moreover, they may be to a greater risk of exposure since they have a larger surface area to volume ratio than adults. Their organs and tissues are still under development and the magnitude of their interaction with the environment can be higher compared to adults since small children have the tendency to put things inside mouth to enhance their experience of the world. Case reports have shown that infant's transdermal exposure alone can lead to systemic effects, due to the differences in permeability and in the activity of metabolic pathways, that can transform a non toxic substance for adults into a toxic substance for children, but data on Nanotoxicology in childhood are lacking [4-6].

Some of the differences of young skin comprise the absence of the stratum conium until the first week after birth, which is known to be the most important outer protective layer versus xenobiotics; moreover skin thickness is age-dependent, with lowest values in the newborns and highest values around the fourth-fifth decade of life [7]. Newborns from the $2^{\text {nd }}-3^{\text {rd }}$ months of age until the entire toddler period have a layer of subcutaneous fat which may act as storage for lipophilic chemicals absorbed through the skin [8]. As a consequence of the aforementioned histological features, 


\section{Advances in Clinical Toxicology}

developing-skin permeability is higher compared to adult skin, especially during the first year of life. This is confirmed by the traditional toxicology knowledge's [9].

No data are available as regards NPs skin absorption through developing skin, which is expected to be higher due to the peculiar histological feature described before. To assess this point in vitro study may represent a useful tool to gain information, since do to ethical reasons they have to be preferred to in vivo studies. Children dermal exposure to NPs is an issue that needs to be addressed, in order to better define which differences may exist with respect to adults and thus to better define their exposure risk. More research efforts are needed in this way.

\section{References}

1. European Commission (EC) (2011) Commission Recommendation of 18 October 2011 on the definition of nanomaterial. OJ L 275: 38-40.

2. Larese Filon F, Mauro M, Adami G, Bovenzi M, Crosera $M$ (2015) Nanoparticles skin absorption: New aspects for a safety profile evaluation. Regul Toxicol Pharmacol 72(2): 310-322.

3. Quadros ME, Pierson R, Tulve NS, Willis R, Rogers K, et al. (2013) Release of silver from nanotechnology- based consumer products for children. Environ Sci Technol 47(15): 8894-8901.

4. Clemens PC, Neumann RS (1989) The Wolff-Chaikoff effect: hypothyroidism due to iodine application. Arch Dermatol 125(5): 705.

5. Shuman RM, Leech RW, Alvord EK (1974) Neurotoxicity of hexachlorophene in the human. 1. A clinicopathologic study of 248 children. Pediatrics 54(6): 689-695.

6. Wysowski DK, Flynt JW, Goldfield M, Altman R, Davis AT (1978) Epidemic neonatal hyperbilirubinemia and use of a phenolic disinfectant detergent. Pediatrics 61(2): 165-170.

7. Burns DA, Breathnach SM, Cox N, Griffiths CE (2004) Rook's Textbook of Dermatology. $7^{\text {th }}$ (Edn.), Malden, Mass: Blackwell Science.

8. Thompson H (1946) Physical growth. In: Manual of Child Psychology Carmichael L (Eds.), New York: John Wiley and Sons, pp: 255-294.

9. Bearer CE (1995) How are children different from adults? Environ Health Perspect-103(6): 7-12. 